\title{
FORECASTING OF THE AMOUNT OF RUPIAH BANKNOTES FLOWS IN THE EAST REGION OF INDONESIA USING CIRCULAR REGRESSION
}

\author{
Jassinca Chrissma Audina ${ }^{1 *}$, Rais ${ }^{2}$, Lilies Handayani ${ }^{3}$ \\ ${ }^{123}$ Tadulako University, Central Sulawesi, Indonesia \\ *e-mail: jassinca.c.audina@gmail.com
}

\begin{abstract}
Money is a tool that can be used in exchanging goods and services in a certain area. Increasing and decreasing in the money supply excessively can have a negative impact on the economy. For this reason, in order to maintain financial system stability in Indonesia, it is necessary to conduct an analysis of the data on the amount of outflows of rupiah currency at each Bank Indonesia office. In this study, a relationship analysis will be carried out between the eastern region of Indonesia and the amount of outflows of Bank Indonesia banknotes during the 2016-2018 period using circular regression analysis. The results showed that $83.03 \%$ of the variation in the amount of outflows of BI banknotes could be explained by the circular regression model that was formed. In addition, in the process of forecasting data on the amount of outflows of BI banknotes in the eastern region of Indonesia for the 2019-2020 period, the time series forecasting method is used which is based on the use of analysis of the relationship pattern between the estimated variables and the time variable.
\end{abstract}

Keywords: Circular Regression, Forecasting, Rupiah Banknotes Outflow

Cite: Audina, J. C., Rais, \& Handayani, L. (2021). Forecasting of the Amount of Rupiah Banknotes Flows in the East Region of Indonesia Using Circular Regression. Parameter: Journal of Statistics, 2(1), 32-39.

Copyright (C) 2021 Audina et al. This is an open-access article distributed under the Creative Commons Attribution License, which permits unrestricted use, distribution, and reproduction in any medium, provided the original work is properly cited. 


\section{INTRODUCTION}

The definition of money is something that is generally accepted as a means of payment in a certain area or as a means of paying debts or as a means to purchase goods and services. In other words, money is a tool that can be used to exchange both goods and services in a certain area (Kasmir, 2011). In the economy, the role of money is very important. It is normal for the money supply to increase or decrease, but excessive increases and decreases in the money supply can have a negative impact on the economy. Therefore, the money supply needs to be adjusted to the economic conditions, which is the role of Bank Indonesia (BI) to carry out this task.

Bank Indonesia is the central bank of the Republic of Indonesia in accordance with Article 23D of the Constitution of the Republic of Indonesia and Act Number 23 of 1999 concerning Bank Indonesia. As the central bank, BI has a single goal, namely to achieve and maintain stability in the value of the rupiah. To achieve this goal, BI is supported by three pillars, which are three areas of its duties as stipulated in Article 8 of Law Number 23 of 1999. These three tasks are to establish and implement monetary policy, regulate and maintain the smooth running of the payment system, and regulate and supervise the Bank. BI is also the only institution that has the right to circulate money in Indonesia (Pemerintah Indonesia, 2007). The need for rupiah at each Bank Indonesia office is based on the amount of inventory, the need for payment, exchange, and replacement of money for a certain period of time (Sigalingging, Setiawan, \& Sihaloho, 2004). Thus, this is necessary to analyze the data on the amount of outflows of rupiah banknotes at each BI office in order to be able to adjust to the amount of rupiah inflows at each BI office each year. This is conducted in order to maintain the stability of the financial system in Indonesia.

The current development of data analysis is still dominant using linear statistics. In statistics, there are other types of data, namely directed data. One type of directed data is circular data, which is data that is measured periodically in the form of an angle or two-dimensional oriented, which is unitary in time or degrees of direction (Jammalamadaka \& Sengupta, 2001). According to Abuzaid, Hussin, and Rambli (2011), linear and circular data have different topological spaces that require different analysis. Therefore, it is not appropriate to analyze circular data using linear statistics, so that circular data needs to be analyzed using circular statistical analysis. Circular statistical analysis is often also used to model data, which is expressed in terms of direction and time.

Statistical analysis that aims to model the causal relationship between the independent variable and the response variable is regression analysis. If there is one independent variable or the response variable is circular data, then the regression analysis used is circular regression analysis (Jammalamadaka \& Sarma, 1988).

Several studies related to the methods and cases in this study are the research conducted by Hidayat (2016) analyzed the relationship between the type of museum and the number of museum visitors in DKI Jakarta using circular regression analysis, which both types of data are circular data. Another study was conducted by Rohazim (2016) with the case of climate data modeling using multiple linear circular regression analysis where the response variable is linear data, while one of the independent variables is circular data. Meanwhile, the research conducted by Maria, Sedana, and Artini (2017) analyzed the effect of interest rates, inflation, and growth in gross domestic product on the money supply in Timor-Leste using multiple regression analysis.

This study raises the case of the number of banknotes outflows through the central office of Bank Indonesia and domestic representative offices of Bank Indonesia in 14 provinces in the eastern region of Indonesia during the 2016-2018 period, then an analysis of the relationship between regions and the amount of banknotes outflows will be conducted using circular regression analysis.

\section{MATERIALS AND METHODS}

\section{Data Sources}

In this research, the process of taking and collecting data is obtained indirectly from the object or research subject, in the other words, it is secondary data. The data used in this study is data on the number of outflows of rupiah banknotes in the eastern region of Indonesia in 2016-2018 based on the division of work units in the 2018 Indonesian Economic Report, which consists of the Provinces of Bali, West Nusa Tenggara, East Nusa Tenggara, West Kalimantan, Central Kalimantan, South Kalimantan, East Kalimantan, North Sulawesi, Central Sulawesi, South Sulawesi, Southeast Sulawesi, North Maluku, Maluku and Papua. 


\section{Research Variables}

In this study, analysis of the relationship between regions consisting of 14 provinces and the total outflows of Bank Indonesia banknotes for the 2016-2018 period will be carried out. Therefore, the response variable used is data on the transformation of the number of outflows of rupiah banknotes in the eastern region of Indonesia for the 2016-2018 period ( $Y$ ), while the independent variables include cos (province) which is data from 14 provinces in eastern Indonesia that repeats for 3 years for the cos function $\left(X_{1}\right)$ and $\sin$ (province) which is data from 14 provinces in the eastern region of Indonesia that repeats for 3 years for the sin function $\left(X_{2}\right)$.

\section{Methods}

The method used in this research is the Circular Regression. The Circular regression analysis is a regression analysis used to evaluate the relationship between the independent variable and the response variable with the response variable or independent being circular data, or the independent variable and the response variable being circular data. According to Mardia and Sutton (1978), the circular regression model is as follows:

$$
Y=M+A_{1} \cos \cos t+A_{2} \sin \sin t+\varepsilon
$$

Where $Y$ is the dependent variable, $M$ is the general mean, $A_{1}$ is the regression parameter for the cos function and $A_{2}$ is the regression parameter for the sin function, and $t$ as the circular independent variable and $\varepsilon_{i}$ is the residual random component.

\section{Data Analysis}

The data analysis design using the circular regression analysis method is as follows:

1. Conducting normality test on the data on the outflow of rupiah banknotes in the eastern region of Indonesia for the 2016-2018 period to find out the distribution of the data.

2. Transforming data on the outflow of rupiah banknotes in the eastern region of Indonesia for the 2016-2018 period into circular form.

3. Forming cos (province) and sin (province) as independent variables by using trigonometric functions sine and cosine from 14 regions and 3 periods.

4. Performing circular regression analysis, using data on the transformation of the total outflow of Bank Indonesia banknotes into circular form as the response variable, as well as the cos (province) and $\sin$ (province) variables as independent variables which are also circular. The stages in circular regression analysis include:

a. Circular regression assumption test

b. Formation of circular regression model

5. Performing goodness of fit test which is measured by using the coefficient of determination $\left(R^{2}\right)$ and the statistical value of $\mathrm{F}$.

6. Forecasting the amount of outflow of rupiah banknotes in the eastern region of Indonesia for the 2019-2020 period.

\section{RESULTS AND DISCUSSION}

\section{Data Transformation}

The determination of whether a linear data needs to be transformed into circular data or not, can be seen from the distribution of the observation data. If the observation data is not normally distributed, it is necessary to handle the data, one of which is by transforming the data with the aim of increasing the suitability of the data with the assumptions that underlie the modeling process, which in this study used circular data transformation.

Conclusions regarding the normality of the observed data will be carried out using the Kolmogorov-Smirnov test to test whether the distribution of the observed sample data is in accordance with the normal distribution or not. If the probability value or $p$-value is greater than the significance level value of 0.05 , then the observation data is normally distributed. Moreover, if the probability value or $p$-value is smaller than the 0.05 level of significance, then the distribution of the observation data is not normal.

The results of the normality test using the Kolmogorov-Smirnov statistical test are obtained as shown in Table 1. 
Table 1. Kolmogorov-Smirnov Test for Initial Data

\begin{tabular}{cc}
\hline $\boldsymbol{D}$ & $\boldsymbol{p}$-value \\
\hline 1.00 & $2.220 \times 10^{-16}$ \\
\hline
\end{tabular}

According to the Kolmogorov-Smirnov test shown in Table, the $D$ statistic value is 1.00 and the $p$-value is $2.220 \times 10^{-16}$. If the value of $D$ is compared with the critical value in the KolmogorovSmirnov statistical quantile table $\left(D_{\text {table }}\right)$, the sample size is $n=42$ and the significance level value is $\alpha=0.05$, which is 0.210 . So, it can be seen that the value of $D>D_{\text {table }}$ and the value of $p-$ value < 0.05 , so the hypothesis rejects $H_{0}$ which means that the residual distribution has a different distribution from the normal distribution. Thus, the observation data needs to be transformed into circular data so that it can then be analyzed using circular regression analysis. The results of the transformation of observational data are obtained by using software R, where in the process, the transformation does not change the data value, but changes the data type into a circular data form.

\section{The Formation of Independent Variables}

The formation of independent variables is carried out using the trigonometric functions of sine and cosine on regional variables, which consist of the names of 14 provinces in the eastern region of Indonesia which are repeated for 3 periods. By using the equations $x=\cos \theta$ and $y=\sin \theta$, the independent variables will be obtained in the form of $\cos$ (province) and $\sin$ (province). The value of $\theta$ is the result of the multiplication between the results of the conversion of regional variables, from categorical form to numerical form, with a value of $\frac{2 p i}{42}$.

\section{Circular Regression Assumption Test}

There are several assumptions that must be met in the circular regression analysis, including normally distributed residuals, homogeneous residual variances, independent residuals, and no correlation between independent variables (multicollinearity does not occur).

\section{Normality Test}

The statistical normality detection is by using the Kolmogorov-Smirnov test. The Kolmogorov-Smirnov test is used to test whether the observed distribution of sample data corresponds to a certain theoretical distribution or not. The theoretical distribution referred to in the normality test is the normal distribution. The test hypothesis, generally written:

$H_{0}: F_{s}(x)=F_{t}(x)$, the residual distribution has the same distribution as the normal distribution $H_{1}: F_{s}(x) \neq F_{t}(x)$, The residual distribution has a different distribution from the normal distribution

By using R software, the value of $D$ for the Kolmogorov-Smirnov test is obtained as follows:

Table 2. Kolmogorov-Smirnov Test

\begin{tabular}{cc}
\hline $\boldsymbol{D}$ & $\boldsymbol{p}$-value \\
\hline 0.103 & 0.725 \\
\hline
\end{tabular}

Furthermore, to draw conclusions on the Kolmogorov-Smirnov test, the statistical value of $D$ in Table 2 is compared with the critical value in the Kolmogorov-Smirnov statistical quantile table $\left(D_{\text {table }}\right)$. At the sample size $n=42$ and the value of the significance level $\alpha=0.05$, the $D_{\text {table }}$ value is 0.210 . Thus, it can be seen that the value of $D<D_{\text {table }}$, so the hypothesis fails to reject $H_{0}$ which means that the residual distribution has the same distribution as the normal distribution. In addition, by comparing the $p$-value with a significance level of 0.05 , it can be concluded that the $p-$ value $(0.725)>0.05$, so the hypothesis also failed to reject $H_{0}$.

\section{Heteroscedasticity Test}

The heteroscedasticity test aims to test whether in the regression model there is an inequality of residual variance from one observation to another. Detecting the homogeneous of residuals variance can be done using the Bartlett formal test. The hypothesis used is as follows:

$H_{0}$ : The residual variance is homogeneous 
$H_{1}$ : The residual variance is not homogeneous

The results of the Bartlett formal test using statistical tests which were obtained using the $\mathrm{R}$ software, can be seen in Table 3.

Table 3. Bartlett Test of Homogeneity of Variances

\begin{tabular}{cc}
\hline Bartlett's $\boldsymbol{K}$-squared & $\boldsymbol{p}$-value \\
\hline 9.995 & 0.694 \\
\hline
\end{tabular}

The conclusion on Bartlett's test can be drawn by comparing the value of Bartlett's $K$ squared $\left(\chi^{2}\right)$ in Table 3 with the value of $\chi_{\alpha, k-1}^{2}$ in the Chi Square table. With a value of $\alpha=$ 0.05 and $k=14$, the value of $\chi_{0.05,13}^{2}$ is 22,362 , where $\chi^{2}<\chi_{0.05,13}^{2}$, which means that the hypothesis fails to reject $H_{0}$ or the variance of the residual is homogeneous. In addition, from the comparison between the $p$-value in Table 3 and the significance level of 0.05 , the $p$-value (0.694) $>0.05$, so it can be concluded that the hypothesis failed to reject $H_{0}$ which means that the residual variance is homogeneous.

\section{Autocorrelation Test}

The autocorrelation test aims to test whether in the regression model there is a correlation between the residuals in the $t$ observation data and the residuals in the $t-1$ observation data. Detecting independent residuals can be done using the Durbin Watson formal test. The hypothesis used is as follows:

$H_{0}$ : The residuals are independent

$H_{1}$ : The residuals are not independent

By using the R software, the results of the Durbin Watson formal test are obtained as shown in Table 4.

Table 4. Durbin Watson Test

\begin{tabular}{cc}
\hline $\boldsymbol{d w}$ & $p$-value \\
\hline 1.881 & 0.253 \\
\hline
\end{tabular}

Based on the results of the Durbin Watson formal test in Table 4, the $d w$ value of 1.881 and the $p$-value of 0.253 were obtained. With a significance level of $0.05, n=42$, and $k=2$, using the Durbin Watson table, the $d_{L}$ and $d_{U}$ values can be obtained, respectively, which are 1,407 and 1,606. Based on the comparison results, it can be seen that the value of $d w(1.881)>d_{U}(1.606)$ or $d w(1.881)<4-d_{U}(2.394)$, so that the hypothesis $H_{0}$ is accepted, it means that there is no autocorrelation or the residuals are independent. In addition, by seeing that the $p$-value $>0.05$, it can be concluded that the hypothesis also fails to reject $H_{0}$ or that the residuals are independent.

4. Multicollinearity Test

The multicollinearity test aims to test whether there is a correlation between the independent variables in the regression model. Multicollinearity detection can be done by calculating the value of Variance Inflation Factor (VIF). The hypotheses used in the multicollinearity test are:

$H_{0}$ : There is no multicollinearity in the regression model

$H_{1}$ : There is multicollinearity in the regression model

The VIF value from the results of the multicollinearity assumption test, which in this observation was obtained using R software, can be seen in Table 5.

Table 5. Variance Inflation Factor (VIF) Value

\begin{tabular}{cc}
\hline Independent Variables & VIF \\
\hline Cos (province) & 2.708 \\
\hline Sin (province) & 2.708 \\
\hline
\end{tabular}


Based on the results of the multicollinearity assumption test in Table 5, the VIF value for each independent variable is 2,708 , where VIF $<10$. Thus, it can be concluded that the hypothesis fails to reject $H_{0}$ which means that there is no multicollinearity in the regression model or between independent variables there is no correlation.

\section{Formation of the Circular Regression Model}

The results of the classical assumption testing that have been carried out in the previous discussion indicate that the data used in this study has met the classical assumptions. Thus, it can be concluded that the circular regression model used in this study has met the Best Linear Unbiased Estimator (BLUE) estimation model and is feasible to be used in regression analysis. Table 6.

Circular regression equation estimates were obtained using the least squares method, as shown in

Table 6. Estimation of Circular Regression Parameters

\begin{tabular}{cccc}
\hline & Estimate & $\boldsymbol{t}$ value & $\boldsymbol{P r}(>|t|)$ \\
\hline (Intercept) & 16586.600 & 4.283 & $1.160 \times 10^{-4} * * *$ \\
\hline Cos (province) & -655.600 & -0.285 & 0.777 \\
\hline Sin (province) & -9138.700 & -2.184 & $0.035 *$ \\
\hline
\end{tabular}

Based on the estimated parameters of the circular regression equation obtained in Table 6 , using the $\mathrm{R}$ software, it is possible to form a circular regression model as follows:

$$
Y=16586.600-655.600 \cos (\text { province })-9138.700 \sin (\text { province })
$$

\section{Goodness of Fit Test}

Statistically, the goodness of fit test will be measured using two values, namely the value of the coefficient of determination $\left(R^{2}\right)$ and the value of the $F$ statistic.

\section{Coefficient of Determination $\left(R^{2}\right)$}

The coefficient of determination $\left(R^{2}\right)$ is one of the statistical values that can be used to measure how far the model's ability to explain the variation of the response variable is. The value of the coefficient of determination used in this study is the adjusted $R$-squared value, this is because many independent variables used in this study consist of more than or equal to two independent variables.

By using the formed circular regression model, the coefficient of determination is obtained as shown in Table 7.

Table 7. Coefficient of Determination Value $\left(R^{2}\right)$

\begin{tabular}{rc}
\hline Multiple $\boldsymbol{R}$-squared & Adjusted $\boldsymbol{R}$-squared \\
\hline 0.8386 & 0.8303 \\
\hline
\end{tabular}

Based on the adjusted $R$-squared value obtained in Table 7 , which is 0.8303 , it can be concluded that $83.03 \%$ of the diversity in the number of outflows of BI banknotes can be explained by the circular regression model formed, while the remaining $16.97 \%$ is influenced by other factors outside model.

\section{2. $\quad F$ Statistic Test}

The $F$ statistic test is basically used to test the feasibility of the model by showing whether all the independent variables included in the model have a joint effect on the response variables or not. The hypothesis used in the F test for this study is as follows:

$H_{0}$ : The independent variables cos (province) and sin (province) simultaneously have no significant effect on the number of outflows of BI banknotes

$H_{1}$ : The independent variables cos (province) and sin (province) simultaneously have a significant effect on the number of outflows of BI banknotes

The results of the simultaneous significant test ( $F$ test) obtained using $\mathrm{R}$ software can be seen in Table 8 below: 
Table 8. Simultaneous Test Results ( $F$ Test)

\begin{tabular}{cc}
\hline $\boldsymbol{F}$-statistic & $p$-value \\
\hline 101.300 & $3.582 \times 10^{-16}$ \\
\hline
\end{tabular}

The $F$ test results shown in Table 8 show that the $F_{\text {count }}$ value of 101,300. This value will be compared with the value from $F_{\text {table }}$ obtained in table $F(\mathrm{DF} 1=2, \mathrm{DF} 2=39, \alpha=5 \%)$, which is 3.240. Based on the comparison results, it is concluded that the value of $F_{\text {count }}>F_{\text {table }}$, so that the hypothesis rejects $H_{0}$ or in other words the independent variables cos (province) and sin (province) simultaneously have a significant effect on the amount of outflow of BI banknotes. Meanwhile, by comparing the $p$-value in Table 8 with the significance level of 0.05 , it will be found that the $p$-value $\left(3,582 \times 10^{-16}\right)<0.05$. Thus, it can be concluded that the hypothesis also rejects $H_{0}$.

\section{6. $\quad$ Forecasting}

The last step in data analysis in this study, namely data forecasting. Forecasting method used in the process of data forecasting on the number of outflows of Bank Indonesia rupiah banknotes in eastern Indonesia for the 2019-2020 period is the time series method, which is based on the use of analysis of the relationship pattern between the estimated variables and the time variable. So that the results of data forecasting on the number of outflows of Bank Indonesia rupiah banknotes in eastern Indonesia for the 2019-2020 period are obtained as shown in Table 9.

Table 9. Forecasting Data

\begin{tabular}{ccc}
\hline \multirow{2}{*}{ Region } & \multicolumn{2}{c}{ Forecasting Data } \\
\cline { 2 - 3 } & $\mathbf{2 0 1 9}$ & $\mathbf{2 0 2 0}$ \\
\hline Bali & 14576.238 & 9850.357 \\
\hline West Kalimantan & 13266.409 & 10851.218 \\
\hline South Kalimantan & 12030.746 & 11980.197 \\
\hline Central Kalimantan & 10896.852 & 13212.075 \\
\hline East Kalimantan & 9890.058 & 14519.334 \\
\hline Maluku & 9032.852 & 15872.770 \\
\hline North Maluku & 8344.383 & 17242.152 \\
\hline West Nusa Tenggara & 7840.032 & 18596.889 \\
\hline East Nusa Tenggara & 7531.063 & 19906.719 \\
\hline Papua & 7424.379 & 21142.382 \\
\hline South Sulawesi & 7522.364 & 22276.275 \\
\hline Central Sulawesi & 7822.827 & 23283.070 \\
\hline Southeast Sulawesi & 8319.058 & 24140.276 \\
\hline North Sulawesi & 8999.972 & 24828.744 \\
\hline
\end{tabular}

\section{CONCLUSION}

Based on the results and discussions that have been carried out in this study, it can be concluded that the circular regression model which is formed based on the parameter estimates obtained has met the classical assumption test. It is also concluded that the independent variables cos (province) and sin (province) together have a significant effect on the data on the number of outflows of BI banknotes, with the coefficient of determination of the circular regression model of $83.03 \%$. In addition, data forecasting on the number of outflows of Bank Indonesia rupiah banknotes in eastern Indonesia for the period 20192020 is carried out using the time series forecasting method which is based on the use of analysis of the relationship pattern between the estimated variables and the time variable. 


\section{REFERENCES}

Abuzaid, A., Hussin, A. G., \& Rambli, A. (2011). COVRATIO Statistic for Simple Circular Regression Model. Chiang Mai J.Sci, 38(3), 321-330.

Hidayat, I. (2016). Pendugaan Jumlah Pengunjung Museum di Provinsi DKI Jakarta Menggunakan Regresi Sirkular. Bogor: Institut Pertanian Bogor.

Jammalamadaka, S. R., \& Sarma, Y. R. (1988). A Correlation Coefficient for Angular Variables. In K. Matusita, Statistical Theory and Data Analysis II (pp. 349-364). Amsterdam: Elsevier.

Jammalamadaka, S. R., \& Sengupta, A. (2001). Topics in Circular Statistics (Vol. V). Singapura: World Scientific.

Kasmir. (2011). Analisis Laporan Keuangan. Jakarta: Raja Grafindo Persada.

Mardia, K. V., \& Sutton, T. W. (1978). A Model for Cylindrical Variables with Applications. The Royal Statistical Society : Series B (Methodological), 40(2), 229-233.

Maria, J. A., Sedana, I. B., \& Artini, L. G. (2017). Pengaruh Tingkat Suku Bunga, Inflansi, dan Pertumbuhan Gross Domestic Product Terhadap Jumlah Uang Beredar di Timor-Leste. EJurnal Ekonomi dan Bisnis Universitas Udayana, 6(10), 3477-3514.

Pemerintah Indonesia. (2007). Undang-Undang Nomor 23 Tahun 1999 tentang Bank Indonesia. Jakarta: Sekretariat Negara.

Rohazim. (2016). Penerapan Analisis Regresi Sirkular pada Pemodelan Data Iklim. Bogor: Institut Pertanian Bogor.

Sigalingging, H., Setiawan, E., \& Sihaloho, H. D. (2004). Kebijakan Pengedaran Uang di Indonesia. Jakarta: PPSK BI. 